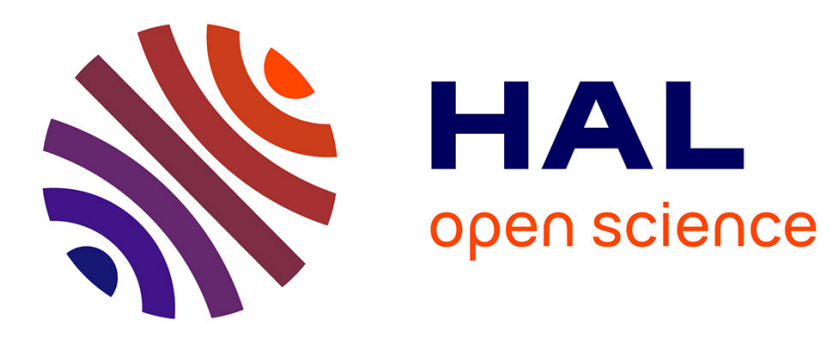

\title{
Optical spectroscopy of Eu3+ doped zinc borate glasses
}

\author{
L. Ambrosi, M. Bettinelli, M. Ferrari, M. Casarin, A. Piazza
}

\section{To cite this version:}

L. Ambrosi, M. Bettinelli, M. Ferrari, M. Casarin, A. Piazza. Optical spectroscopy of Eu3+ doped zinc borate glasses. Journal de Physique IV Proceedings, 1994, 04 (C4), pp.C4-477-C4-480. 10.1051/jp4:19944114 . jpa-00252564

\section{HAL Id: jpa-00252564 https://hal.science/jpa-00252564}

Submitted on 1 Jan 1994

HAL is a multi-disciplinary open access archive for the deposit and dissemination of scientific research documents, whether they are published or not. The documents may come from teaching and research institutions in France or abroad, or from public or private research centers.
L'archive ouverte pluridisciplinaire HAL, est destinée au dépôt et à la diffusion de documents scientifiques de niveau recherche, publiés ou non, émanant des établissements d'enseignement et de recherche français ou étrangers, des laboratoires publics ou privés. 


\title{
Optical spectroscopy of $\mathrm{Eu}^{3+}$ doped zinc borate glasses
}

\author{
L. AMBROSI, M. BETTINELLI ${ }^{*}$, M. FERRARI ${ }^{* *}$, M. CASARIN and A. PIAZZA**
}

Dipartimento di Chimica Inorganica, Metallorganica ed Analitica, Università di Padova, via Loredan 4, 35131 Padova, Italy

${ }^{*}$ Facoltà di Scienze MM. FF. NN., Università di Verona, Ca'Vignal, Strada Le Grazie, 37100 Verona, Italy

${ }^{* *}$ CNR, Centro di Fisica degli Stati Aggregati ed Impianto Ionico, via Sommarive 14, 38050 Povo (TN), Italy

\begin{abstract}
Zinc borate binary glasses of composition $4 \mathrm{ZnO} .3 \mathrm{~B}_{2} \mathrm{O}_{3}$ undoped and doped with $0.5 \% \mathrm{~mol}$ of $\mathrm{Eu}^{3+}$ were prepared from the melt giving rise to samples of excellent optical quality. In the present work we use the spectroscopic properties of the $\mathrm{Eu}^{3+}$ to obtain information about the structural and dynamic features of our system. Different optical techniques such as site selection, excitation spectroscopy and lifetime measurements as well as Raman spectroscopy were used to study the local environment of the $\mathrm{Eu}^{3+}$ ion in these glasses. No energy transfer is observed at our concentration and moreover non-radiative relaxation from the excited ${ }^{5} \mathrm{D}_{0}$ state to the ${ }^{7} \mathrm{~F}_{5}$ manifold is not important. A broad distribution of slightly different environments of the $\mathrm{Eu}^{3+}$ ion is reflected in the trend of the Stark splittings of the ${ }^{7} \mathrm{~F}_{1}$ state and in the crystal field parameters for the individual sites as a function of the excitation wavelength. Phonon sidebands are observed in the excitation and luminescence spectra of the $\mathrm{Eu}^{3+}$ impurity. We make an attempt to assign these sidebands to coupling of the vibrational modes of the structural units containing the $\mathrm{Eu}^{3+}$ ion. The strength of the electron-phonon coupling is evaluated and compared with the result obtained for related systems.
\end{abstract}

\section{Introduction}

Although vibrational spectroscopic studies on some borate glass systems have been reported $[1,2,3]$, there are no extensive investigations, using the luminescence properties, on the zinc borate binary glasses $4 \mathrm{ZnO} \cdot 3 \mathrm{~B}_{2} \mathrm{O}_{3}: \mathrm{Eu}^{3+}$. Nevertheless this system is very easy to prepare and samples of good optical quality can be obtained. In order to use these doped rare earths glasses as optical devices it is important to know the effects of the matrix on the spectroscopic properties of the optically active ion [4,5]. At this aim we have performed excitation spectra, fluorescence spectra and lifetime measurements on the ${ }^{5} \mathrm{D}_{0} \leftrightarrow{ }^{7} \mathrm{~F}_{0}$ transition of $\mathrm{Eu}^{3+}$ ions in this glass. For our purposes this is a helpful transition. In fact it involves only levels with $J=0$ and thus has no internal structure. Moreover it is relatively strong in our sample. Raman spectra for the doped and undoped glasses have been used to detect possible localized vibrational modes around the Europium.

\section{Experimental}

Emission and excitation spectra were obtained using a FL 2001 Dye Laser with rhodamine $6 \mathrm{G}$, pumped by EMG50 Lambda Physik Excimer laser. The fluorescence was focused onto a model 1401 double Spex monochromator equipped with a cooled RCA C31034A02 photomultiplier tube and was detected 
by photon counting. Both emission and excitation measurements were performed in time-resolved spectroscopy. Lifetime measurements were performed on a model SR430 Stanford multichannel using a minimum dwell time of $2.56 \mu \mathrm{s}$. An Oxford Instruments cryostat was used for low-temperature measurements. Raman spectra were measured on a double monochromator Ramanor HG $2 \mathrm{~S}$ JobinYvon, using the $514.5 \mathrm{~nm}$ line of a Spectra Physics 166 argon-ion laser, operating at $250 \mathrm{~mW}$. Resolution of the Raman spectra was about $2 \mathrm{~cm}^{-1}$. We used two scattering geometries with the incident beam polarized perpendicular $(\mathrm{V})$ or parallel $(\mathrm{H})$ to the scattering plane. The scattered radiation, measured at an angle of $90^{\circ}$ from the incident laser beam, was the sum of the radiation polarized in the both directions (T). We call these geometries as V-T and H-T respectively.

\section{Results and Discussion}

The room temperature Raman spectra of the undoped and doped samples are shown in Figure 1 and Figure 2 respectively. Both geometries V-T and $\mathrm{H}-\mathrm{T}$

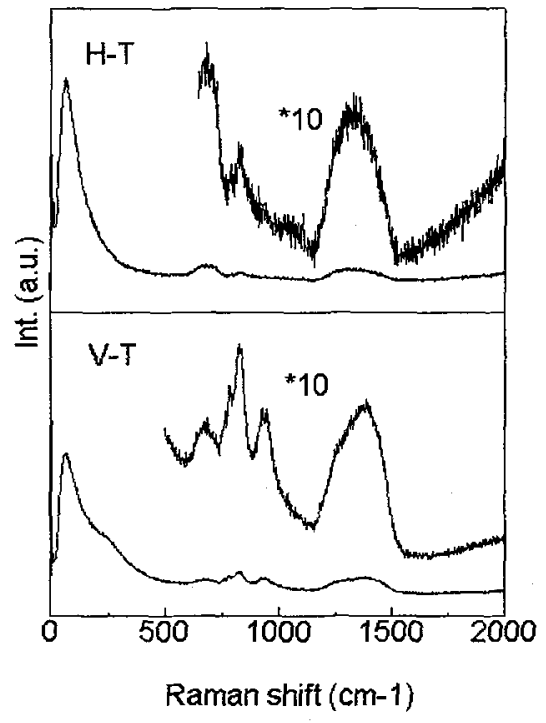

Figure 1: Room temperature Raman spectra of the undoped sample

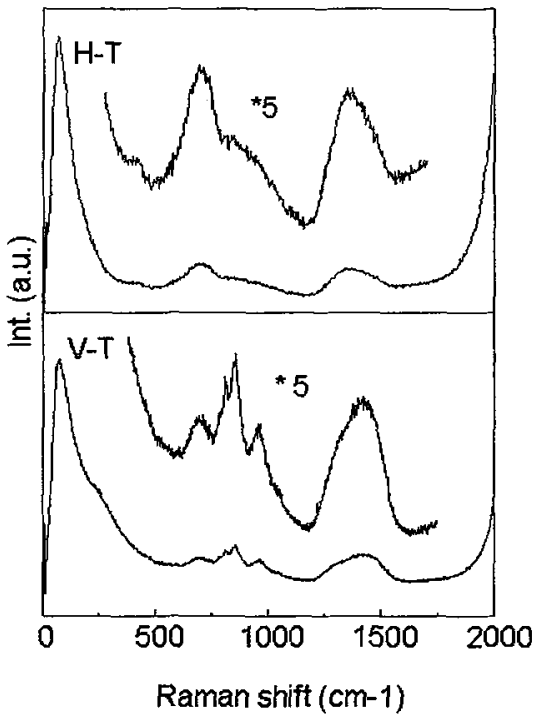

Figure 2: Room temperature Raman spectra of the doped sample

have been recorded. The low-frequency unpolarized broad band at $63 \mathrm{~cm}^{-1}$ is the "boson peak" characteristic of glasses [6]. The features of the spectra at higher energy are similar to those reported for binary metaborate glasses in several papers $[2,7,8]$, where the assignment of the vibrational modes of the borate 
groups is discussed in detail. For the objectives of this work it is enough to observe the strongly polarized structures in the region between 600 and 1100 $\mathrm{cm}^{-1}$ and the unpolarized broad band centered at about $1380 \mathrm{~cm}^{-1}$. These bands are assigned to the vibrational modes of borate groups whose energy and intensity are dependent on the amount of $\mathrm{ZnO}$ modifier. A completely polarized band appears at about $230 \mathrm{~cm}^{-1}$ related to $\mathrm{Zn}-\mathrm{O}$ vibrational mode. In this connection we should recall that Raman bands in the region between 100 and $300 \mathrm{~cm}^{-1}$ have been observed in $\mathrm{Zn}\left(\mathrm{PO}_{3}\right)_{2}$ glasses [9]. The main feature of the Raman spectra for the doped sample, shown in Fig.2, is the polarized H-T band at about $445 \mathrm{~cm}^{-1}$. Its intensity increases with the dopant concentration as shown by the Raman spectra of a sample doped with 2\% mol of Europium. Moreover the low temperature excitation spectrum of the ${ }^{7} \mathrm{~F}_{0} \rightarrow{ }^{5} \mathrm{D}_{0}$ transition, pictured in Fig. 3, displays a phonon sideband at about $445 \mathrm{~cm}^{-1}$ from the zerophonon line. The measure was performed detecting at 16270

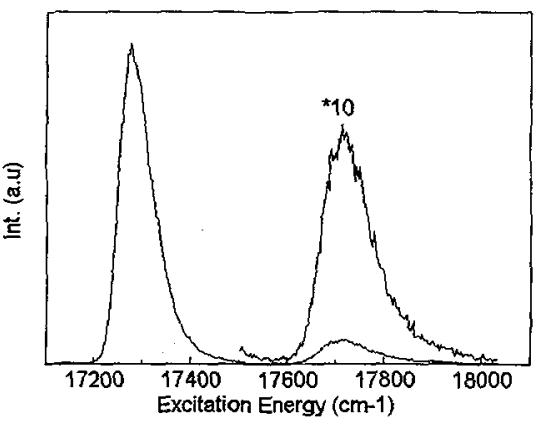

Figure 3: Excitation spectrum of the ${ }^{7} \mathrm{~F}_{0} \rightarrow{ }^{5} \mathrm{D}_{0}$ region at $\mathrm{T}=12 \mathrm{~K}$ $\mathrm{cm}^{-1}$, i.e. on the maximum of the ${ }^{5} \mathrm{D}_{0} \rightarrow{ }^{7} \mathrm{~F}_{2}$ transition. We assign this sideband to localized vibrational modes around $\mathrm{Eu}^{3+}$. A rough evaluation of the electron-phonon coupling strength gives us a value $g$ about 0.11 . Phonon sidebands of $\mathrm{Eu}^{3+}$ associated with the ${ }^{7} \mathrm{~F}_{0} \rightarrow{ }^{5} \mathrm{D}_{2}$ transition have been investigated in sodium borate glasses [10]. In $\mathrm{B}_{2} \mathrm{O}_{3}-\mathrm{Na}_{2} \mathrm{O}$ glasses, where the phonon sideband is observed at about $1000 \mathrm{~cm}^{-1}, \mathrm{~g}$ is about 10 times lower than in our system.

The usual transitions from ${ }^{5} \mathrm{D}_{0}$ to ${ }^{7} \mathrm{~F}_{J}(\mathrm{~J}=0,1,2,3,4)$ states were observed in the low temperature inhomogeneous luminescence spectrum. The two main features are the relatively strong intensity of the superforbidden ${ }^{5} \mathrm{D}_{0} \rightarrow{ }^{7} \mathrm{~F}_{0}$ transition, centered at $17320 \mathrm{~cm}^{-1}$, and the well defined three Stark sublevels of the ${ }^{5} \mathrm{D}_{0} \rightarrow{ }^{7} \mathrm{~F}_{1}$ transition. Also the ${ }^{5} \mathrm{D}_{0} \rightarrow{ }^{7} \mathrm{~F}_{2}$ transition shows internal Stark structures in the region between 15550 and $16500 \mathrm{~cm}^{-1}$. Luminescence from the higher excited states ${ }^{5} D_{J}(J=1,2,3)$ has been not observed due to the non-radiative relaxation towards ${ }^{5} \mathrm{D}_{0}$ induced by the phonons of the matrix. For rare earths [11], the energy difference between the electronic levels below which considerable quenching of the fluorescence occurs is about four phonons. The main vibrational modes in our sample are shown in the Raman spectra of Figure 1 . We can see that the highest optical phonon energy is about $1380 \mathrm{~cm}^{-1}$. This means that in Europium doped borate glasses fast non-radiative relaxations among the excited states toward the lowest one ${ }^{5} \mathrm{D}_{0}$, due to the vibrational modes 
of the matrix, are quite efficient [12] with the energy gaps being not higher than $5500 \mathrm{~cm}^{-1}$. Instead non-radiative transitions from the excited ${ }^{5} \mathrm{D}_{0}$ state to the ground ${ }^{7} \mathrm{~F}_{\mathrm{J}}$ manifold are not important because the energy gap is too large. This is confirmed by lifetime measurements. The luminescence decay from the ${ }^{5} \mathrm{D}_{0}$ state presents a single exponential profile and the observed lifetime is nearly the same at room temperature $(\tau=1.650 \mathrm{~ms})$ as at $T=12 \mathrm{~K}(\tau=1.690 \mathrm{~ms})$ within the experimental incertitude. The relative intensity of the ${ }^{5} \mathrm{D}_{0} \rightarrow{ }^{7} \mathrm{~F}_{0}$ transition observed in our sample is stronger than in other borate systems; for instance in sodium borate glasses [13] and in $\mathrm{LaCaZrSiB}_{2} \mathrm{O}_{3}$ glasses [4]. This could suggest a stronger effect of the linear crystal field terms due to the peculiar structure of $4 \mathrm{ZnO} .3 \mathrm{~B}_{2} \mathrm{O}_{3}$ crystal which consists of boron-oxygen tetrahedra arranged in a ring formation of 6 boron atoms and 12 oxygen atoms [3]. In this case the $\mathrm{Eu}^{3+}$ will be in a site with a coordination number with the surrounding oxygen atoms that can be higher that the usual number of eight [11]. The intensity of the distortion is confirmed by the ${ }^{7} \mathrm{~F}_{1}$ energy splitting of about $200 \mathrm{~cm}^{-1}$ higher that the 140 $\mathrm{cm}^{-1}$ observed in other borax systems [11]. The ${ }^{5} \mathrm{D}_{0} \rightarrow{ }^{7} \mathrm{~F}_{0}$ is a transition between single levels and thus has no internal structure. Its inhomogeneous linewidth gives a measure of the energy distribution of the different $\mathrm{Eu}^{3+}$ sites [5]. We observed no structures inside this inhomogeneous broad line and measure a $\mathrm{FWHM} \approx 130 \mathrm{~cm}^{-1}$ at $12 \mathrm{~K}$ that reflects a continuous site-distribution induced by slight differences in the environment of the $\mathrm{Eu}^{3+}$ ion. The linewidth measured at room temperature by fluorescence line narrowing method is about $5 \mathrm{~cm}^{-1}$ at $17320 \mathrm{~cm}^{-1}$ for the $0.5 \%$ mol doped sample, that means a homogeneous linewidth of about $2.5 \mathrm{~cm}^{-1}$. We observed no time evolution in the shape of the line at different delay from the excitation. Therefore, the intraline energy transfer is negligible in our sample as confirmed by lifetime measurements as well as by site selection measurements in time resolved spectroscopy.

\section{References}

1. E.I.Kamitsos, M.A.Karakassides, A.P. Patsis and G.D. Chryssikos J. Non-Crystalline Solids 116, 115, (1990).

2. W.L.Konijnendijk and J.M.Stevels, J. Non-Crystalline Solids 18, 307, (1975).

3. I.A. Harris,Jnr and P.J.Bray, Physics Chem. Glasses 25, 69, (1984).

4. J.A. Capobianco, P.P. Proulx, N.Raspa, D.J. Simkin and D.Krashkevich, J.Chem.Phys. 90, 2856, (1989).

5. C.Brecher and L.A.Riseberg, Phys. Rev. B 13, 81, (1976).

6. E.Duval,A.Boukenter and T.Achibat, J.Phys.:Condens.Matter 2, 10227, (1990).

7. C.B.Layne, W.H.Lowdermilk and M.J.Weber, Phys.Rev B 16, 10, (1977).

8. E.I. Kamitsos, M.A. Karakassides and G.D. Chryssikos, J.Phys.Chem. 91, 1073, (1987).

9. P.P. Proulx, J.A. Capobianco, B. Champagnon and M. Bettinelli, J.Phys.:Condensed Matter, (1993) in press

10. S.Tanabe, S.Todoroki, K.Hirao and N.Soga, J. Non-Crystalline Solids 122, 59, (1990).

11. R. Reisfeld, Structure and Bonding 13,53,(1973).

12. R. Reisfeld, Structure and Bonding 22, 123, (1975).

13. M. Zahir, C. Parent, R. Olazcuaga, G. Le Flem and P.Hagenmuller, J. Non-Cryst. Solids 81, 53, (1986). 